\title{
STUDI KINETIKA DAN ISOTERM ADSORPSI TIMBAL(II) PADA KULIT JENGKOL (Pithecellobium jiringa) TERAKTIVASI
}

\author{
(Study of Kinetics and Isotherm Adsorption of Lead(II) on Jengkol's Peel \\ (Pithecellobium jiringa) Activated)
}

\author{
Gatut Ari Wardani ${ }^{1 *}$, Winda Trisna Wulandari ${ }^{1}$ \\ 1) Prodi Farmasi, STIKes Bakti Tunas Husada Tasikmalaya \\ Tasikmalaya, Indonesia \\ *) Coresponding Author : gatutariwardani@stikes-bth.ac.id (hp : 085228051957)
}

Diterima 15 Agustus 2017, Disetujui 7 Oktober 2017

\begin{abstract}
The use of waste of jengkol's leather for lead(II) ion adsorption has been successfully done. The jengkol's peel used is the waste comes from one of the traditional market in Tasikmalaya City. Firstly, the leather of jengkol was activated by using nitric acid before used as an adsorbent. The optimum time which needed by jengkol's leather to adsorb lead(II) ion is 30 minutes with the percent of adsorbed ion as much as $60.694 \%$. Adsorption kinetics of lead(II) at jengkol's leather follows the kinetic model of pseudo two Ho with the value of $R^{2}$ is 0.995 and the value of $k$ is 1.984 minutes ${ }^{-1}$. Adsorption isotherm of lead(II) at jengkol's leather follows Freunlich's adsorption model with the value of $R^{2}$ as much as 0.980 and adsorption capacity is about $0.554 \mathrm{mg} / \mathrm{g}$.
\end{abstract}

Keyword: lead, jengkol's leather, kinetics adsorption, adsorption isotherm

\begin{abstract}
ABSTRAK
Penggunaan limbah kulit jengkol untuk mengadsorpsi ion timbal(II) telah berhasil dilakukan. Kulit jengkol yang digunakan merupakan limbah dari salah satu pasar tradisional di Kota Tasikmalaya. Kulit jengkol diaktivasi terlebih dahulu menggunakan asam nitrat sebelum digunakan sebagai adsorben. Waktu optimum yang dibutuhkan kulit jengkol untuk mengadsorpsi ion timbal(II) adalah 30 menit dengan persen ion teradsorpsi sebesar $60,694 \%$. Kinetika adsorpsi timbal(II) pada kulit jengkol mengikuti model kinetika pseudo dua Ho dengan nilai $R^{2}$ sebesar 0,995 dan nilai $k$ sebesar 1,984 menit $^{-1}$. Isoterm adsorpsi dari timbal(II) pada kulit jengkol mengikuti model adsorpsi Freunlich dengan nilai $R^{2}$ sebesar 0,980 dan kapasitas adsorpsi sebanyak $0,554 \mathrm{mg} / \mathrm{gram}$.
\end{abstract}

Kata kunci: timbal, kulit jengkol, kinetika adsorpsi, isoterm adsorpsi 
LATAR BELAKANG

Logam berat sebagai zat pencemar perairan sangat berbahaya bagi kelangsungan hidup makhluk hidup. Timbal merupakan diantara beberapa jenis logam berat yang dapat menimbulkan pencemaran dalam air. Tingkat toksisitas yang tinggi dari logam Timbal dapat membahayakan kesehatan masyarakat dalam waktu lama. Industri bahan bakar, baterai, pengecoran logam dan industri kimia lainnya dapat menjadi jalan masuknya logam timbal ke dalam lingkungan perairan (Safrianti dkk., 2012).

Menurut Ashraf dkk. (2010), prosesproses pemisahan ion logam umumnya memerlukan biaya yang cukup besar dan mempunyai efektivitas yang rendah apabila diterapkan pada konsentrasi rendah. Dengan demikian, cara mengolah limbah logam berat yang tepat dan efisien dengan tidak memerlukan banyak biaya masih terus dibutuhkan hingga saat ini. Biosorpsi merupakan salah satu metode yang dapat digunakan menjadi alternatif dalam mengatasi masalah tersebut.

Bahan biomaterial yang dimanfaatkan dalam proses biosorpsi sangat mudah diperoleh dengan biaya yang relatif murah sehingga metode ini dapat digunakan sebagai alternative dalam pengolahan limbah logam berat (Alluri dkk., 2007). Proses biosorpsi dapat mengikat ion logam berat seperti ion timbal(II) melalui langkah-langkah metabolism maupun kimia fisika. Proses pengolahan ini tidak memerlukan proses pemindahan limbah karena dapat dilakukan ditempat. Beberapa keuntungan yang dapat diperoleh dalam pemakaian biosorben diantaranya yaitu bahan baku yang mudah diperoleh, proses pengolahan yang efisien, ekonomis, dan merupakan proses regenerasi (Ashraf dkk., 2010). Menurut Isnaini dkk. (2013), kulit buah jengkol (Pithecellobium jiringa) merupakan salah satu bahan biomaterial yang dapat menyerap ion logam. Limbah kulit buah jengkol dimungkinkan dapat digunakan sebagai bahan yang mampu mengurangi kadar logam berat seperti logam timbal $(\mathrm{Pb})$. Penelitian ini akan mengkaji kinetika dan isotherm adsorpsi logam timbal(II) pada limbah kulit jengkol teraktivasi asam nitrat.

\section{METODE PENELITIAN}

\section{Alat dan Bahan}

Bahan-bahan yang digunakan dalam penelitian ini adalah limbah kulit buah jengkol, asam nitrat $\left(\mathrm{HNO}_{3}\right)$, timbal nitrat $\left(\mathrm{Pb}\left(\mathrm{NO}_{3}\right)_{2}\right)$, dan akuabides. Peralatan yang digunakan dalam penelitian ini antara lain adalah peralatan gelas laboratorium, magnetic stirrer, ayakan, stopwatch, neraca analitik, oven, spektrometer serapan atom (SSA, ContrAA 300), spektrometer FTIR (Simadzu).

\section{Prosedur Penelitian}

\section{Aktivasi Limbah Kulit Jengkol}

Kulit buah jengkol dibersihkan dari kotoran-kotoran yang menempel. Kulit buah jengkol yang sudah terlepas dari 
kotorannya dicuci dan dibersihkan dengan akuabides. Setelah bersih, kemudian dikeringkan dibawah sinar matahari sampai kering. Kulit buah jengkol yang sudah kering dihaluskan dan diayak menggunakan mesh ukuran 100 mesh. Serbuk kulit jengkol kemudian disimpan dalam botol kedap udara dan diambil 0,5 gram untuk dianalisis gugus fungsinya dengan menggunakan spektrometer FTIR.

\section{Studi Kinetika Adsorpi (Widihati dkk.,} 2012)

Sebanyak 0,125 gram serbuk kulit buah jengkol direndam dengan $25 \mathrm{~mL}$ larutan $\mathrm{Pb}\left(\mathrm{NO}_{3}\right)_{2} \quad 5 \mathrm{ppm}$. Campuran kemudian diaduk menggunakan magnetic stirrer pada suhu ruang. Waktu interaksi divariasikan selama $0,5,15,30$, dan 45 menit. Filtrat diambil sebanyak $10 \mathrm{~mL}$ dan kemudian dianalisa menggunakan spektrometer serapan atom (SSA) untuk mengetahui jumlah ion timbal(II) yang tersisa dalam larutan.

Studi Isoterm Adsorpsi (Andreas dkk., 2008)

Sebanyak 0,125 gram serbuk kulit buah jengkol direndam dengan $25 \mathrm{~mL}$ larutan $\mathrm{Pb}\left(\mathrm{NO}_{3}\right)_{2}$. Konsentrasi timbal(II) divariasikan sebesar 10, 15, 20, dan 25 ppm. Campuran kemudian diaduk menggunakan magnetic stirrer pada suhu ruang selama 30 menit. Filtrat diambil sebanyak $10 \mathrm{~mL}$ dan kemudian dianalisa menggunakan spektrometer serapan atom (SSA) untuk mengetahui jumlah ion timbal(II) yang tersisa dalam larutan.

\section{HASIL DAN PEMBAHASAN}

\section{Adsorben dari Limbah Kulit Jengkol}

Limbah kulit jengkol yang digunakan untuk mengadsorpsi timbal(II) perlu diaktivasi terlebih dahulu. Aktivasi bertujuan untuk memperbanyak jumlah sisi aktif adsorben sehingga dapat meningkatkan daya serapnya (Sudiarta, 2009). Spektra IR menunjukkan adanya pergeseran-pergeseran peak yang mengindikasikan adanya perubahan kerangka struktur dari kulit jengkol setelah proses aktivasi. Spektra IR menunjukkan adanya pergeseran serapan gugus hidroksi $(-\mathrm{OH})$ dari $3264,12 \mathrm{~cm}^{-1}$ menjadi $3414,92 \mathrm{~cm}^{-1}$. Pergeseran bilangan gelombang ke arah bilangan gelombang yang lebih panjang menunjukkan terjadinya peningkatan energi dan kekuatan ikatan.

Perendaman dengan asam nitrat juga berfungsi untuk memutuskan lignin dari kompleks lignoselulosa. Proses pemutusan lignin diperlukan karena lignin dapat menutupi gugus hidroksil selulosa pada biosorben dengan membentuk ikatan kovalen dengan kromofor-kromofor lignin (Royana dkk., 2016) . Hal ini dapat dibuktikan dengan menurunnya serapan gugus $\mathrm{C}=\mathrm{C}$ aromatis lignin $\left(1522,20 \mathrm{~cm}^{-1}\right)$.

\section{Kinetika Adsorpsi}

Kinetika adsorpsi dipelajari dengan cara menginteraksikan larutan timbal(II) dengan kulit jengkol teraktivasi. Pola adsorpsi ion logam pada kulit jengkol dipengaruhi oleh waktu dan dapat dilihat 
pada Gambar 1. Daya adsorpsi diketahui terus meningkat sampai menit ke 30 . Setelah adsorpsi selama 30 menit diperoleh jumlah maksimal logam timbal(II) yang terserap yaitu sebesar 60,694\%. Kesetimbangan adsorpsi diperoleh setelah adsorpsi 15 menit yang ditandai dengan grafik yang cenderung landai.

Model kinetika adsorpsi dipelajari dari pola adsorpsi terhadap waktu. Dari data yang diperoleh pada Gambar 1, dilakukan kajian kinetika adsorpsi yang

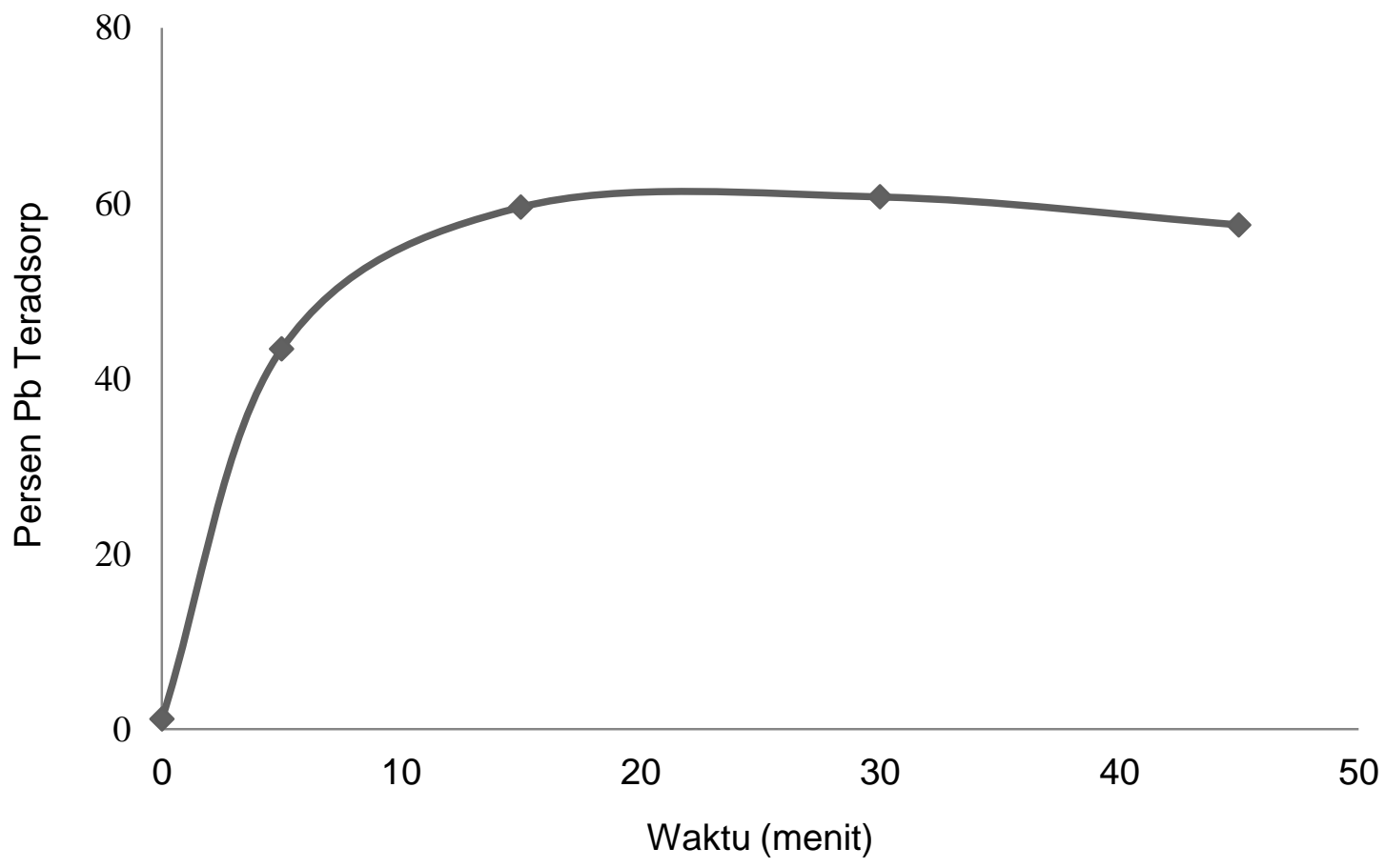

Gambar 1. Pola adsorpsi ion timbal(II) pada kulit jengkol teraktivasi terhadap waktu

Tabel 1. Hasil analisis model kinetika adsorpsi logam timbal pada kulit jengkol

\begin{tabular}{lccc}
\hline Model kinetika & Persamaan Linear & $\begin{array}{c}\text { Konstanta Laju } \\
\text { Adsorpsi, } k\left(\text { menit }^{-1}\right)\end{array}$ & Linearitas \\
\hline $\begin{array}{l}\text { Santosa } \\
\text { Langmuir- }\end{array}$ & $\mathrm{y}=0,017 \mathrm{x}+0,146$ & 0,017 & $\mathrm{R}^{2}=0,581$ \\
Hinshelwood & $\mathrm{y}=0,005 \mathrm{x}+0,240$ & 0,005 & $\mathrm{R}^{2}=0,519$ \\
Ho & $\mathrm{y}=1,690 \mathrm{x}+1,439$ & 1,984 & $\mathrm{R}^{2}=0,995$ \\
\hline
\end{tabular}


Berdasarkan Tabel 1, maka dapat diketahui bahwa adsorpsi logam timbal(II) pada kulit jengkol teraktivasi mengikuti model kinetika pseudo dua Ho. Hal ini dikarenakan pada model kinetika Ho menghasilkan linearitas yang tinggi dengan nilai $R^{2}$ sebesar 0,995 dan konstanta laju adsorpsi $(k)$ adalah 1,984 menit ${ }^{-1}$.

\section{Isoterm Adsorpsi}

Hubungan antara jumlah timbal(II) yang teradsorpsi pada kulit jengkol dengan konsentrasi timbal(II) dalam fasa cair pada temperatur tertentu disebut dengan adsorpsi isotermis. Dari analisis yang diperoleh, maka dapat disajikan kurva adsorpsi isoterm Langmuir dan Freundlich (Gambar 2).

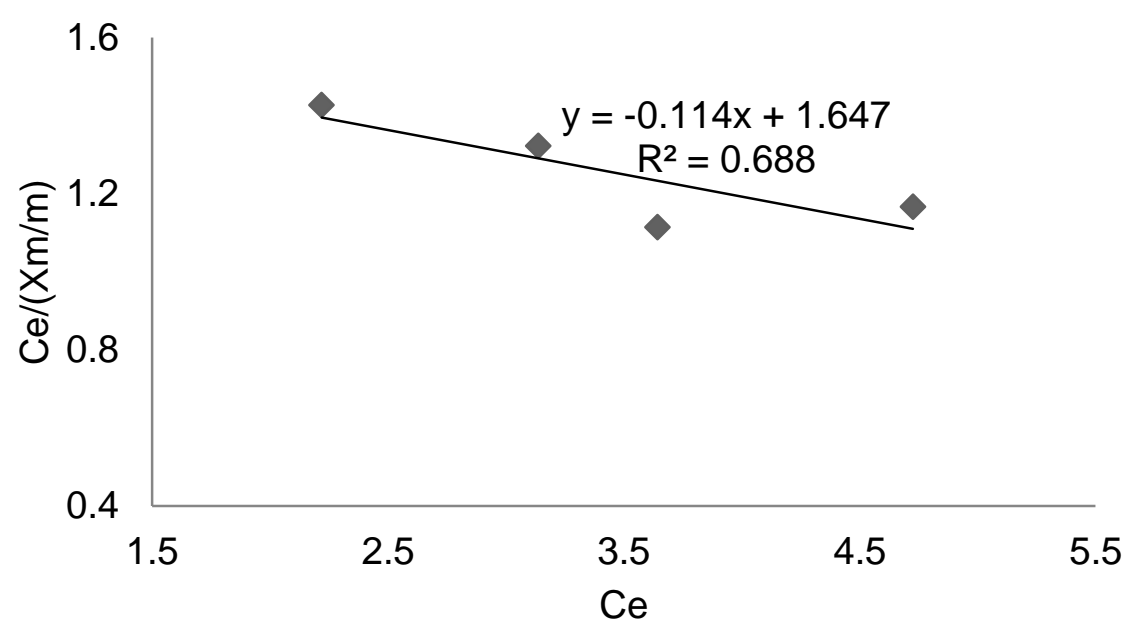

(a)

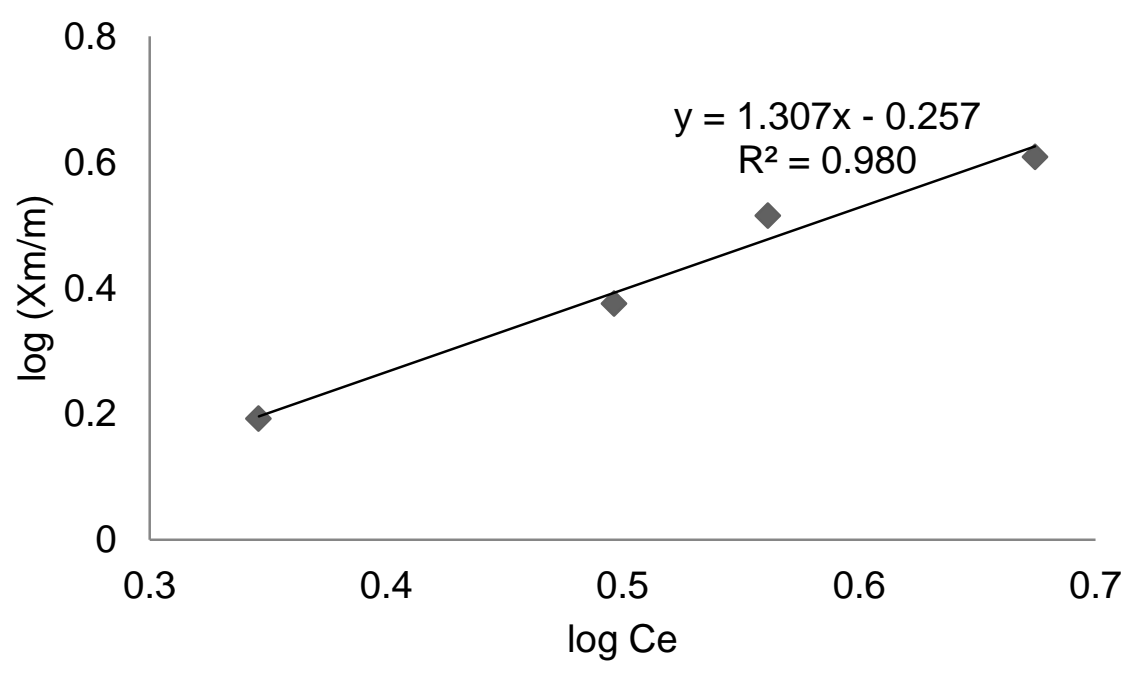

(b)

Gambar 2. Model adsorpsi isotermal Langmuir (a) dan Freundlich (b) 
Berdasarkan Gambar 2, maka dapat dilihat bahwa adsorpsi logam timbal(II) oleh kulit jengkol teraktivasi mengikuti model adsorpsi isotermal Freundlich dengan nilai $\mathrm{R}^{2}=0,980$. Parameter adsorpsi yang diperoleh antara lain adalah $k=0,554$ dan $n=0,765$. Dengan demikian, adsorben dari kulit jengkol mempunyai permukaan yang heterogen dan tiap sisi aktif mempunyai kemampuan adsorpsi yang berbeda. Berdasarkan analisis dan perhitungan menggunakan model isoterm adsorpsi Freundlich diperoleh kapasitas adsorpsi sebesar $0,554 \mathrm{mg} / \mathrm{g}$.

\section{KESIMPULAN}

Adsorpsi logam timbal(II) oleh limbah kulit jengkol telah berhasil dilakukan dengan waktu adsorpsi optimum 30 menit. Dalam waktu tersebut kulit jengkol mampu menyerap ion timbal(II) sebanyak 60,694\%. Kinetika adsorpsi mengikuti model Ho dengan nilai $R^{2}=0,995$ dan nilai $k=1,984$ menit $^{-1}$. Isoterm adsorpsi mengikuti model adsorpsi Freundlich dengan nilai $R^{2}=0,980$ dan kapasitas adsorpsi sebesar 0,554 $\mathrm{mg} / \mathrm{gram}$.

\section{UCAPAN TERIMAKASIH}

Ucapan terima kasih disampaikan secara khusus kepada DRPM Kemenristekdikti yang telah mendanai penelitian ini melalui program hibah Penelitian Dosen Pemula Tahun 2017.

\section{DAFTAR PUSTAKA}

Alluri, H.K., Ronda, S.R., Sttaluri, V.S., Singh, Bondili, J.S., Suryanarayan, V., Venkateshwar, P. 2007. Biosorption: An Eco-friendly alternative for heavy metal removal. Afr. J. Biotechno., 6(25): $2924-2931$.

Andreas, R., Sulaeman, U., Setyaningtyas, T. 2008. Pemanfataan Karbon Sabut Kelapa Terimpregnasi untuk Mengurangi Tembaga(II) dalam Medium Air. Molekul. 3(2): 91-97.

Ashraf, M.A., Maah, M.J., Yusoff, I. 2010. Study of Banana peel (Musa sapientum) as a Cationic Biosorben. American-Eurasian J. Agric \& Environ. Sci, 8(1): 7-17.

Isnaini, P., Zein, R., Munaf, E. 2013. Penyerapan Ion $\mathrm{Cd}(\mathrm{II})$ dan $\mathrm{Zn}(\mathrm{II})$ dalam Air Limbah Menggunakan Kulit Jengkol (Pithecellobium jiringa Prain), J. Kim. Unand, 2(3): 20 -30.

Royana, I., Kurniawan, R., Yulianti, E., Mahmudah R. 2016. Pemanfaatan Biosorben Batang Jagung Teraktivasi Asam Nitrat dan Asam Sulfat untuk Penurunan Angka Peroksida - Asam Lemak Bebas Minyak Goreng Bekas. AICHEMY: J. Chem, 5(1): 10-18.

Safrianti, I., Wahyuni, N., Zaharah, T.A. 2012. Adsorpsi Timbal (II) oleh Selulosa Limbah Jerami Padi Teraktivasi Asam Nitrat: Pengaruh $\mathrm{pH}$ dan Waktu Kontak. JKK, 1(1): 1-7.

Sudiarta, W. 2009. Biosorpsi ion $\operatorname{Cr}($ III) pada rumput laut Euchema spinosum teraktivasi asam sulfat. Jurnal Kimia, 3(2): 93-100.

Widihati, I.A.G., Suastuti, N.G.A.M.D.A., Nirmalasari, M.A. 2012. Studi Kinetika Adsorpsi Larutan Ion Logam Kromium (Cr) Menggunakan Arang Batang Pisang (Musa paradisiaca). Jurnal Kimia. 6(1): 8-16. 